\title{
Enabling Law and Policy Environment for Climate Technology Transfer: From Perspectives of Host Countries
}

\section{Chen Zhou*}

Climate friendly technologies contribute to tackling global climate crisis and the dynamic transfer of these technologies is important to achieve universal climate actions. The UNFCCC, and its recent Paris Agreement, have introduced international assistance to promote climate related-technology transfer. They call for collaborative actions from both technology supplier and demander sides in order to enable environments for a meaningful and effective technology transfer. According to the UNFCCC, the international technology assistance is unlikely to work in a desired way with the absence of indigenous enabling environments. Therefore, it is crucial to identify, assess and overcome potential barriers potentially confronted by host countries in their acquisition of climate technologies, which helps prepare these countries for climate resilience economy and sustainable development. This paper attempts to provide a deep and comprehensive analysis on enabling policy/law environments in host countries and uses Asian countries as examples in most occasions.

\section{Keywords}

Climate Change, Technology Transfer, Host Countries, Demander, Enabling Environment

* Professor Assistant of international environmental law at Xiamen University. LL.M. (Wuhan), Ph.D. (Tilburg). ORCID: https://orcid.org/0000-0002-8461-2738. This research was supported by the research program of "Addressing Climate Change and The Synergic Control of Air Pollutions" (0130/K1300001), Starting-Up Research Fund of China Scholarship Council. The author may be contacted: czhou@xmu.edu.cn / Address: South Siming Road 422, The Law School of Xiamen University, Siming District, Xiamen, Fujian Province, P.R. China 


\section{Introduction}

Climate change is a global common concern and the combat of it requires all possible solutions. In this process, technology solutions would play profound roles because they serve for reducing greenhouse gases ("GHGs") emission, optimizing energy structure, and promoting low carbon economy and society. Today, there is a worldwide consensus that the development and transfer of climate friendly technologies contribute to local capacity building, thereby promoting the compliance of climate agreements ultimately. The United Nations Framework Convention on Climate Change 1992 ("UNFCCC") has recognized technology transfer as international assistance. It has also required facilitating the development of climate technologies and their dynamic transfer on a global scale. The recent Paris Agreement aims to strengthen the global response to the threat of climate change, which in many aspects committed its members to tighten cooperation on climate technologies.

Despite the necessary role of technologies, the real world shows a different picture: climate technologies are transferred at an inadequate rate, ${ }_{1}^{1}$ particularly in light with the requirements of the UNFCCC and the urgency of [addressing] global climate crisis. The reasons behind this gap are complex. From the perspective of technology demander, the absence of enabling policy/law environments in host countries (mostly developing countries in practice) largely undermines a meaningful and effective technology transfer. It is thus significant to identify, analyze, and assess these potential barriers that hinder smooth crossing-border technology flows in a comprehensive and constructive manner.

\section{A. The Key Needs of Host Countries}

Participatory development is seen as imperative to achieve all-round, multi-channel technology transfer. ${ }^{2}$ This development includes the efforts of both technology supplying and demanding countries, and the public and private sectors. Although the international transfer of climate technology depends primarily on suppliers, ${ }^{3}$ it is difficult for the suppliers to play a desired role in the absence of sound indigenous

1 T. Heller \& P. Shukla, Beyond Kyoto-Advancing the International Effort against Climate Change, THE PEw CENTER ON Global Climate Change 115 (2003).

2 IPCC, Climate Change 2014: Impacts, Adaptation and Vulnerability (Summary for Policymakers) (2014), available at https://www.ipcc.ch/site/assets/uploads/2018/02/ar5_wgII_spm_en.pdf (last visited on May 28, 2019).

3 U.N. Doc. FCCC/TP/2003/2 (Feb. 4, 2003), available at https://unfccc.int/resource/docs/tp/tp0302.pdf (last visited on May 27, 2019). 
environments. From a perspective of the life-cycle of technology, the entire process of technology transfer will not be over unless advanced technologies are successfully adapted to local circumstances and ultimately improve climate/environmental quality. In practice, the international efforts for the implementation of technology transfer provisions are shifting from a push approach to a push-and-pull approach. ${ }^{4}$ It has been realized that climate technology transfer driven by the donor-push approach only is less likely to succeed without recipient-pull assistance. ${ }^{5}$

The first step of the push-and-pull approach is to identify the key needs of both technology supplier and demander sides. ${ }^{6}$ From the angle of host technology demanders, poverty and underdevelopment - which are characterized by poor capital markets, inferior technologies, and unsound institutions-result in development which favors fossil-fueled energy generation. ${ }^{7}$ These countries are suffering the 'lock-in' effects of high carbon, which takes a time to break through. "If advanced climate technology is not applied in time, the technological lock-in effect will lead to several decades of higher GHGs emission in those countries." ${ }^{8}$ It is thus important to recognize the priorities of these countries to further eradicate poverty and pursue a healthy, inner-balanced and sustainable development. As the UNFCCC stated, the efforts for climate change mitigation and adaptation is an inclusive part of countries' wider development agenda. ${ }^{9}$ Thereafter, climate change-related technology transfer involves overall building capacity, which itself contributes to local development agenda.

\section{B. The Approach}

Despite the differences among host technology countries-such as their development stages, technology endowments, and political-legal basis-they are urging for an effective international technology transfer to increase the flows of technology for

4 S. Lechtenböhmer, Copenhagen Plus: Complementing Output-oriented Climate Policy with Input-Oriented Approaches, 6 ENVTL. EARTH SCI. 21-2 (2009).

5 Xiliang Zhang, Enabling the Transfer of Environmentally Sound Technologies in the Context of Climate Change: Some Lessons from Asia 23 (2000), available at https://unfccc.int/files/documentation/workshops_documentation/ application/pdf/xiliang.pdf (last visited on May 28, 2019).

6 Supra note 1, at 111.

7 C. Deal, Climate Change Technology Transfer: Opportunities in the Developing World, ASME WISE INT'L 7 (2007). See also M. Goodwin \& H. Somsen, Regulating for Climate Change in Developing Countries: Appropriate Regulatory Strategies in the Context of Technology Transfer, 2 NoRdiC J. INT'L L. 113 (2010).

8 Zou Ji, Pang Jun \& Wang Haiqin, Technology Transfer under the UNFCCC Framework, in Cumate Change IN AsIA: Perspectives on the Future Climate Regime 183-4 (Y. Kameyama \& P. Agus eds., 2008).

9 Paris Agreement art. 4(1). 
climate change mitigation and adaptation. "What remains common to all cases is the desirability of a supportive regulatory framework, and enabling environment more generally, together with the circulation of knowledge and capabilities among individuals and institutions in host countries." 11 In this regard, in practice, these countries are bound to seriously erase legal uncertainties and address regulatory, institutional obstacles. ${ }^{12}$

In the meanwhile, due to inadequate information and enormous differences, there is no "one-size-fits-all" approach to be provided in the remaining content. ${ }^{13}$ Instead, this article will focus on general and critical practices concerning host technology demanders, in which Asian countries are used as examples in many occasions. Therefore, above all, what has been formulated on technology transfer by the UNFCCC proceedings, from a particular perspective of technology demander? This paper is composed of four parts including Introduction and Conclusion. Part two will discuss legal framework. Part three will examine legal barriers.

\section{Legal Framework}

Climate change-related technology transfer is broadly regulated by the UNFCCC, which originated at the United Nations Conference on Environment and Development (Convention) as early as $1992 .{ }^{14}$ The UNFCCC mandated technology transfer obligations for its Parties in general following three principles: (1) the common but differentiated responsibilities principle; (2) the cooperation principle; and (3) the best [technologies] available principle.

10 A. Latif, The Climate Technology Mechanism: Issues and Challenges, 5:4 BIORES 2 (2011), available at https://www. ictsd.org/bridges-news/biores/news/the-climate-technology-mechanism-issues-and-challenges (last visited on May 27, 2019).

11 GEF/C.34/05/Rev.01 (Nov. 13, 2008) available at https:/www.thegef.org/sites/default/files/council-meeting-documents/ C.34.5.Rev_.1_4.pdf (last visited on May 29, 2019).

12 U.N. Doc. FCCC/SBI/2010/INF.4 (May 26, 2010).

13 B. Hoekman, K. Maskus \& K. Saggi, Transfer of Technology to Developing Countries: Unilateral and Multilateral Policy Options, 33 World Dev. (2005).

14 In 1992, the Rio Earth Summit succeeded in delivering the Rio Declaration, Agenda 21 and the UNFCCC. Since then, the transfer of climate friendly technologies has been taken on a new urgency in international environmental policies and laws. 


\section{A. The Commitments under the UNFCCC}

According to the UNFCCC, developing countries are major and the most important advocators for climate technologies. These countries had no compulsory emission reduction targets, and would receive international technological and financial assistance for the use of addressing domestic climate crisis. This is the well-known "international [solidarity] assistance." 15 International assistance was based on the fact that the atmospheric system is a global public good (the common concern of human kind) and climate change is a historically accumulative problem. More specifically, industrialized country Parties are obligated to take the lead practical steps to reduce GHGs and facilitate the transfer of climate technologies to developing country Parties, while the main task of other country Parties is to focus on domestic climate change mitigation and adaptation by virtue of international solidarity assistance.

\section{The Conditionality Clause}

The Convention introduced the conditionality clause in Article 4.7. In a legal sense, Article 4.7 is unique because it does not attempt to introduce any concrete commitments but provide conditions to fulfill existing commitments. ${ }^{16}$ In fact, several Multinational Environment Agreements ("MEAs") have adopted the conditionality clause, ${ }^{17}$ which makes the fulfillment of developing countries conditional on the actions taken by developed countries. Under the clause, developing country Parties could suspend the implementation of the UNFCCC if developed country Parties did not provide financial assistance and technology transfer. Therefore, it might be fair to say that the conditionality clause makes financial assistance and the transfer of technology indispensable for the implementation of MEAs. ${ }^{18}$ Consequently, a violation of the provisions on international solidarity assistance may constitute a material breach and is in conflict for the purpose of the Convention. ${ }^{19}$

\section{Enabling Environment}

Since technology transfer commitments are critical for achieving the purpose of the

15 E. Rehbinder, The Principle of Common But Differentiated Responsibilities and Global Climate Protection, Conference on Energy Security and Climate Changes for Policies and Law in China and Europe 5 (2013).

16 Qin Tianbao, The Study of Basic Principles of International Environmental Law [国际环境法基本原则初探], 10 LEGAL RES. [法学]102 (2001). <available only in Chinese>

17 Montreal Protocol art. 5(5). See also Convention on Biological Diversity, art. 20.4.

18 G. Verhoosel, Beyond the Unsustainable Rhetoric of Sustainable Development: Transferring Environmentally Sound Technologies, 49 Geo. InT’L EnvtL. L. Rev. 66 (1999).

$19 \quad I d$. at 61. 
Convention, these commitments need facilitation measures to promote compliance. Thus, Article 4 of the UNFCCC was formulated to require stakeholders enabling their environments for an effective transfer of technology.

As demanders, host (developing) countries may not be able to control the supply of technologies. ${ }^{20}$ If they provided sound environments at every stage of technology transfer, they would still be highly likely to facilitate this process. For instance, they could provide favorable market environments to initially attract foreign investments. ${ }^{21}$ At the stage of the acquisition of technologies, host countries are expected to simplify procedures, provide multi-channels, and guarantee stable environments to increase the interest and security of investors. Once technologies have been acquired, they enable to accommodate foreign technologies soon and use these advanced technologies to improve climate situation. In short, the process of enabling environment is to increase the institutional feasibility of technology transfer in an indigenous context. ${ }^{22}$

\section{B. From the UNFCCC to the Paris Agreement}

In line with international climate negotiations, the UNFCCC has been developed to be more pragmatic, specific, and stringent. Arrays of new arrangements further solidify technology transfer commitments and have improved relevant practices. ${ }^{23}$ Firstly, there were structural improvements like the creation of the Facilitation Branch (FB) and, more importantly, the establishment of Technological Mechanism. Technology Executive Committee ("TEC") and Climate Technology Centre and Network ("CTCN") were created under the Technological Mechanism. Particularly, the CTCN is to provide technology-related assistance on the demand of host developing countries with technology needs assessment, capacity building, and form an international network of climate-related stakeholders. ${ }^{24}$ It is now working closely with the World

20 IPCC Report, WGIII, ch. 2.7.3. (International Dimension in Technology Development and Deployment: Technology Transfer, 2007).

21 These are, for example, national institutions for technology innovation, the involvement of social organizations, human and institutional capacities for selecting and managing technologies, macroeconomic policy frameworks, and the support of sustainable markets for environmentally sound technologies, national legal institutions that reduce risk and protect intellectual property rights, codes and standards.

22 OeCD, Development Environmental Capacity: A Framework for Donor Involvement 10-22 (1995). Factors that impact institutional feasibility are various, including service/maintenance infrastructures, technology capacity, institutional capacity, and dominant tradition/cultures.

23 Technology Mechanism was established in 2010 to support efforts to accelerate and enhance action on climate change, which consists of the Technology Executive Committee and the Climate Technology Centre and Network.

24 A Climate Technology Centre and Network is one of the components of the Technology Mechanism. At the request of a developing country Party: it will (1) provide advice and support related to the identification of technology needs 
Intellectual Property Organization ("WIPO"), through an initiative called 'WIPO Green' that aims at identifying real technology needs of host countries. ${ }^{25}$ Secondly, new mechanisms were introduced. For instance, the Kyoto Protocol made flexible arrangements, in particular the Clean Development Mechanism ("CDM"). As an important vehicle for technology transfer to developing countries, the CDM forms a constructive link between international assistance and Certified Emission Reductions ("CERs"). ${ }^{26}$ Although the mechanism does not have an explicit technology transfer mandate, it serves as a practical tool to finance emission reduction projects that employ clean technologies currently unavailable in host countries. So far, apart from business-as-usual practices, the CDM helps the public and private sectors in developing countries to directly acquire climate friendly technologies. In addition, the UNFCCC aims at the problem-solving approach. It mandated technology need assessment ("TNA") to increase need to match technology transfer. The UNFCCC also endeavored to identify best practices in industry for rapid technology diffusion and dissemination through national and international platforms (such as the CNCT), which improves performances on a case-by-case term.

Until very recently, the landmark Paris Agreement was ratified to keep a rise in global temperature to below 2 degrees Celsius. As an important response to climate threat, the Paris Agreement is welcomed in many aspects, partly because its outcome commits nations to strengthening cooperation on climate technology. In its Preamble, the Agreement confirms, the best [technology] available principle: "recognizing the need for an effective and progressive response to the urgent threat of climate change on the basis of the best available scientific knowledge." 27 Comparatively speaking, the Paris Agreement made three key points with regard to technology transfer: (1) innovation, (2) holistic and balanced approaches, and (3) technology framework. The first key point is technology innovation. The Agreement requires facilitating access to technology for early stages of the technology life cycle to developing country Parties. ${ }^{28}$ A poor national innovation system often leads to a weak knowledge base in

and the implementation of environmentally sound technologies, practices and processes; (2) facilitate the provision of information, training and support for programs to build or strengthen capacity of developing countries to identify technology options, make technology choices and operate, maintain and adapt technology; and (3) facilitate prompt action on the deployment of existing technology in developing country Parties based on identified needs.

25 WIPO, WIPO Green: The Marketplace for Sustainable Technology, available at https://www3.wipo.int/wipogreen/en (last visited on Apr. 10, 2019).

26 Kyoto Protocol art. 12. Under the CDM, the first global, environmental investment and credit scheme is introduced to provide a standardized emission offset instrument - CERs. When GHGs are generated in a CDM project activity, an equivalent quantity of CERs are issued and finally forwarded from the Executive Board to the project participants.

27 Paris Agreement arts. $4 \& 5$.

28 Id. art. 10(5). 
host countries that have problems of fully absorbing the transferred technologies. ${ }^{29}$ Therefore, "help[ing] developing countries establish a mechanism of technological innovation is also an important part of technology transfer." 30 The second key point is new approaches. Technology-related activities under the national determined contributions ("NDCs") are requested to be conducted in an integrated, holistic, and balanced non-market term. ${ }^{31}$ First of all, the Agreement calls for collaborative actions among all stakeholders such as governments, private sector entities, financial institutions, NGOs, and research/education institutions. ${ }^{32}$ Secondly, the new approaches aim at non-market measures. The SBSTA had been requested to undertake a Work Program under the framework for non-market approaches, with the objective of "considering how to enhance linkages and create synergy between inter alia, mitigation, adaptation, finance, technology transfer and capacity building, and how to facilitate the implementation and coordination of non-market approaches." 33 The third key point is technology framework. The Paris Agreement calls on a "Technology Framework" ("TF") to guide the existing mechanisms and institutions such as the TEC and the CTCN in the medium to long-term. The establishment of TF is confronting with challenge of accommodating existing instruments, such as the CDM. There are criticisms that the CDM is driven by CERs rather than technology transfer ${ }^{34}$ and the market of CDM has been distributed uneven among the developing countries group. ${ }^{35}$ It is highly possible that under the proposed $\mathrm{TF}$, the CDM will be reformed to a greater or lesser extent. However, how to reform the CDM remains uncertain.

Although the UNFCCC and its recent Paris Agreement accommodate a wide variety of approaches needed to technology transfer, inherent deficiencies would exist. The range of climate technologies is vast under the current framework and their application covers many sectors. In this regard, "the implicit or perceived disagreement on what constitutes technology transfer-and hence what are the Countering the Climate Changes 12-3 (DIR Research Series Working Paper No. 147, 2011), available at https:// docplayer.net/31121714-The-analysis-of-the-relationship-between-clean-technology-transfer-and-chinese-intellectualproperty-countering-the-climate-changes-min-hao.html (last visited on May 27, 2019).

31 Paris Agreement art. 6(8).

32 Id. art. 10(6).

33 SBSTA 44 Item $11 \mathrm{c}$ (May 21, 2016).

34 K. Murphy et al., Technology Transfer in the CDM: An Updated Analysis, 15 Climate Pol'y 127-45 (2013).

35 L. Chiti et al., Developing Host Country Legal Frameworks for the Clean Development Mechanism, ChITI \& PARTNERS 3-4 (2012), available at $\mathrm{http} / / /$ rema.gov.rw/dna/fileadmin/user_upload/pdf-Documents/CDM_Legal_Framework.pdf (last visited on May 28, 2019). 
technology-related obligations under the UNFCCC-might be at the heart of some of the contentiousness around technology institutions in the UNFCCC." ${ }^{\text {, }}$ Moreover, there are divergences on the legal nature of climate technologies: to what extent they are public good or global common good, and how to govern them effectively in international law system. ${ }^{37}$ These significant deficiencies result in various barriers, hindering the smooth transfer of climate technologies in a real world scenario.

\section{Legal Barriers of Climate Technology Transfer in Host Countries}

Today, global climate governance is fragmented. ${ }^{38}$ It is somehow true that, even within host countries, their circumstances, needs and interests over climate technology transfer are different. ${ }^{39}$ Nevertheless, this article focuses on the big context which is barely changed and shares common barriers blocking an accessible, affordable, and adaptable climate technology transfer. These barriers among host countries can be found in areas of: (1) inadequate capacity, (2) poor policy/law framework, and (3) weak implementation and enforcement.

\section{A. The Lack of Adequate Capacity}

The host countries should deal with the continuing lack of capacity, which is a well-known barrier, because governments are regarded as major actors in creating enabling environments. ${ }^{40}$ In the transfer of climate technology, inadequate capacity can be traced in: (1) innovation system, (2) information management, (3) market mechanism, and (4) the capacity of technology absorption.

\section{Poor Innovation System}

"The priority area relating to strengthening national systems of innovation and technology innovation centres is of importance, as this may be the first time that the concept of 'innovation' has been given such a prominent standing in UNFCCC

\footnotetext{
36 H. Coninck \& A. Sagar, Technology in the 2015 Paris Climate Agreement and beyond, 42 InNovation \& IP 8 (2015).

37 IPCC Report, WGIII, ch.13.3 (International Climate Change Agreements and Other Arrangements, 2007).

38 H. Asselt, Dealing with the Fragmentation of Global Climate Governance, Legal and Political Approaches in Interplay Management, 30 Global Governance 8 (2007).

39 Supra note 15, at 18.

$40 \quad$ Supra note 8, at 187.
} 
decisions on technology transfer." "A1 As aforementioned, the Paris Agreement highlights technology innovation and calls for a collaborative approach to facilitate research and development and access to technology, in particular for early stages of the technology cycle, to developing country parties. ${ }^{42}$

Although many host countries have started to develop climate technologies and made rapid achievements, their overall technology levels has been still lag behind. ${ }^{43}$ In recent practices, national and regional innovation systems have been established all over the world so as to primarily increase technology independence. ${ }^{44}$ However, the perceived weaknesses embedded in the history and reality of host countries still affect the development of technology innovation. These weaknesses vary from country to country. For example, India has historically suffered from a lack of liberalism in industry and the fragmentation of certain key sectors, such as the steel sector. ${ }^{45}$ Nonetheless, India has good tradition of innovation and relatively strong knowledge base at national level. Conversely, China is featured for its huge market size, but poor innovation system. To strengthen its national knowledge base, China recently conducted the "Science Creation and Technology Innovation" strategy on a national scale, in which energy and low-carbon technologies were prioritized. ${ }^{46} \mathrm{~A}$ number of technology innovation centers that focus on mitigation technologies have been established in the last decade, but they have not operated very effectively. ${ }^{47}$ The centers are poorly linked with local manufacturers. ${ }^{48}$ The implementation capacity of these centers is supposed to be substantially increased with financial self-sufficiency, international collaboration to better mobilize the existing resources ${ }^{49}$ such as the TM, and financial means via the FM under the Convention. In addition, there is a lack of social atmosphere and cultural tradition that profoundly promote innovation-driven

41 Supra note 8, at 10.

42 Paris Agreement art. 10(5).

43 C. Hutchison, Does TRIPS Facilitate or Impede Climate Change Technology Transfer into Developing Countries?, 3 TRIPs \& Climate Change 528-30 (2006).

44 W. Kojo, Technology Development and Transfer in the Context of Climate Change Negotiations, UNFCCC Focal Point/CDM-DNA Environmental Protection Agency, Special Session of the African Ministerial Conference on Environment 24 (2009).

45 S. Mani, Institutional Support for Investment in Domestic Technologies: An Analysis of the Role of Government in India, 71 Tech. Forecasting \& Social Change 855-63 (2004).

46 Qingyun Wang, Premier Li Keqiang Calls for Innovation and Creativity, State Council of PRC News, Aug. 23, 2014, available at http://english.gov.cn/premier/news/2014/09/01/content_281474984998321.htm (last visited on Apr. 10, 2019).

47 U.N. Doc. FCCC/TP/2003/1 (Nov. 26, 2003).

48 J. Watson, Cleaner Coal Technology Transfer to China: A Win-Win Opportunity for Sustainable Development? 1 INT'L J. Tech. Transfer \& Commercialization 352-7 (2002).

49 IPCC Report, WGIII, ch. 2.2.3 (Developing Countries' Actions, 2001). 
development. ${ }^{50}$

\section{Immature Information Management}

There is a general mismatch between new and replacement technologies due to asymmetric information between [technology] suppliers and demanders. ${ }^{51}$ This mismatch happens in not only native business, but also international trade. Particularly, the asymmetry of information is very likely to be exacerbated when it comes to the trans-boundary technology transition. Domestic technology demanders usually find it difficult to access information about foreign climate technologies. ${ }^{52}$

Two reasons account for this information barrier mainly. First, there are insufficient channels and practicably inefficient guides provided for domestic demanders to obtain knowledge about available technologies. Therefore, to overcome the information barrier involves systematic capacity-building, including the establishment and management of information infrastructures as well as the introduction of supporting regulations. Latin America used to and currently faces challenges in collecting and organizing information on the economic, environmental and social performances of specific technology ${ }^{53}$ It is impossible to conduct scientific research without fundamental data on topics such as historical meteorology, hydrology and remote sensing data. In some extreme cases such as Nigeria, there is no comprehensive statistical data on the condition of the atmosphere. ${ }^{54}$ It is thus essential for these countries to set up and improve basic information infrastructures like climate observation systems and information management systems, in order to provide fundamental information for technology-related activities like innovation, international transfer, and localization. ${ }^{55}$ The UNFCCC, for instance, its CTCN aims to address these information-based barriers with the TNA and Capacity Building. Host countries, in particular their private sectors, are now tasked with working with the $\mathrm{CTCN}$ to facilitate communication between networks of national, regional,

50 Xiaoying Ma \& L. Ortolano, Environmental Regulation in China: Institutions, Enforcements, and Complance $135-42$ (2000).

51 UNFCCC Secretariat, Third Synthesis Report on Technology Needs Identified by Parties not Included in Annex I to the Convention (2013), at 28 .

52 G77 \& China, Proposal by The G77 \& China for A Technology Mechanism under the UNFCCC (Sept. 29, 2008), available at $\mathrm{http} / / \mathrm{unfccc}$.int/files/meetings/ad_hoc_working_groups/lca/application/pdf/technology_proposal_g (last visited on Apr. 10, 2019)

53 Id.

54 J. Shepherd, The Future of Technology Transfer under Multilateral Environmental Agreements, 37 ELR NEws \& AnALYsis 10560 (2007), available at https://elr.info/sites/default/files/articles/37.10547.pdf (last visited on May 29, 2019).

55 Supra note 10, at 4. 
sectoral, and international technology centers. ${ }^{56}$ Second, there are potentially racing interests between technology suppliers and demanders. Information about cost, use and origin of technology has not been thus fully provided to the market. ${ }^{57}$ Some technology suppliers, in practice, are reluctant to share information because of concerns of intellectual property right or that of an international competitive edge. ${ }^{58}$ Being unaware of the full range of alternatives, demanders tend to be blind and easily 'dumped' by the outdated technologies or technologies they do not really need. ${ }^{59}$ They in reality are also prone to accepting agreements with additional conditions beyond technology transfer, such as the construction, operation, and maintenance of manufacturing plants, or accepting technology packages which often include outdated technologies or technologies irrelevant to local needs. ${ }^{60}$ The solution to this relies, in a broader sense, on appropriate adjustments on the international intellectual property regime, which has been an important topic of climate negotiations. For instance, how to fully fulfill the commitment of information disclosure in the process of technology transfer, as stipulated in Article 29 of TRIPs. ${ }^{61}$

\section{Unsound Climate Technology Market}

A hospitable environment, in which key stakeholders could be incentivized in a full and delicately-balanced manner, is expected to be in place. Very often, such environments are absent in host countries because of market and government failures.

\section{a. Market Failure}

On a global scale, carbon market is recent phenomenon. Until now, this market has been developed rather uneven among regions and is heavily influenced by national

56 J. Morgan, Y. Dagnet \& D. Tirpak, Elements and Ideas for the 2015 Paris Agreement, at 5 (World Resources Institute ed., 2015), available at https://www.wri.org/publication/elements-and-ideas-2015-paris-agreement (last visited on May 27, 2019).

57 See GEF, Transfer of Environmentally Sound Technologies: The GEF Experience (2016), available at https://www. thegef.org/sites/default/files/publications/GEF_TTbrochure_final-lores_3.pdf (last visited on Apr. 10, 2019).

58 M. Littleton, The TRIPS Agreement and Transfer of Climate Change-Related Technologies to Developing Countries, 33 Natural Resources F. 239 (2008).

59 T. Forsyth, Climate Change Investment and Technology Transfer in Southeast Asia, in Climate Change and East Asia: The Politics of Global Warming in China and East Asia 244 (P. Harris ed., 2003).

60 D. Haug, The International Transfer of Technology: Lessons that East Europe Can Learn from the Failed Third World Experiences, 5 HARV. J. L. \& TeCH. 218 (1999).

61 TRIPs art. 29. According to Article 29, once an invention is patented, its disclosure must be carried out "in a sufficiently clear and sufficiently clear and complete for the invention to be carried out by a person skilled in the art." 
politics and international negotiations. ${ }^{62}$ Particularly among host countries, carbon markets are generally immature. ${ }^{63}$ Apparently, carbon market is of necessary importance, because it recognizes that the government plays a central role for the cost of carbon. The price of carbon is the key to transferring low carbon technology. ${ }^{64}$ However, not only host countries, but also the world as a whole, are now confronted with the difficulties of creating and sustaining such a market. "One of the reasons that many low carbon technologies are uneconomic is that the externality they are designed to address, i.e., climate change, is not priced; whilst the inclusion of the environmental and social cost for carbon emissions will not be enough to finance all low carbon technologies." ${ }^{\circ 5}$ The solution for this, and further developing carbon market and relevant technology market therefore relies on rational cost-benefit assessments on climate change.

\section{b. Government Failure}

Where market fails, governmental intervention is needed. With regard to the climate technology market, governments take a role in creating and maintaining a stipulatorily favorable market with, for instance, better transparency, policy stability and predictability.

First, as required in the Paris Agreement, the performances of international technology transfer would be reviewed under the UNFCCC (i.e., with measurable, reportable, and verifiable rules). The Agreement thus obligates the governments of host countries to improve transparency comprehensively. ${ }^{66}$ From an angle of foreign technology suppliers, transparency is necessary to allow them to structure contracts that correspond best with their specific circumstances. ${ }^{67}$ They must be assured that they are entering a market "where all requirements are presented up front and openly with no types of bribes or other forms of corruption necessary to operate." 68

62 IPCC Report, WGIII, ch.2.2.3 (Developing Countries' Actions, 2001).

63 UNFCCC Secretariat, Third Synthesis Report on Technology Needs Identified by Parties not Included in Annex I to the Convention (2013); Second Synthesis Report on Technology Needs Identified by Parties not Included in Annex I to the Convention (2009).

64 D. Ockwell et al., UK-India Collaboration to Identify the Barriers to the Transfer of Low Carbon Energy Technology, Department for Environment, Food and Rural Affair Final Report 40 (2007), available at https://www.academia. edu/33845661/UK_-_India_Collaboration_to_Identify_the_Barriers_to_the_Transfer_of_Low_Carbon_Energy_ Technology (last visited on May 28, 2019).

65 Id. at 46.

66 Paris Agreement art.13(4).

67 J. Peace \& T. Juliani, Carbon Market Oversight and Regulation, PoINT CARBOn News, Mar. 5, 2010, available at http:// www.pewclimate.org/press-center/article/carbon-market-oversight-and-regulation (last visited on Apr. 10, 2019).

$68 \quad$ Supra note 7 , at 17. 
However, poor transparency resulting from historical and realistic situations is still prevailing among technology demander countries. In carbon markets that are highly policy-oriented, transparency is even harder to guarantee. Usually, the information of CERs is not completely disclosed to the commodity markets as needed. ${ }^{69}$ Therefore, to improve transparency is the key first step.

Secondly, the lack of favorable, predictable policy context is another major barrier to import foreign climate technologies. ${ }^{70}$ As aforementioned, carbon market is characterized as a statutorily-created market which fluctuates in line with policies and may send weak signals to relevant technology activities. ${ }^{71}$ Therefore, if governments welcome large-scaled low carbon technologies, they must increase supportive policies/laws. This can be achieved by incentivizing clean industry and preventing unfair competitions like restrictive business practices. In India, for example, "a large part of the economy is dominated by state enterprises and the remainder is heavily regulated, leading to diminished or non-existent incentives to use energy efficiently." ${ }^{, 72}$ It is evidenced that monopoly-dominated marketplaces and price distorting subsidies have frustrated investments from outside India. ${ }^{73}$ The situation in India is better now due to a series of reformations. The far-reaching but incomplete structural-and-economic transitions currently taking place in host countries, especially in some advanced developing countries, have immense impacts on the flows of technology towards more climate-friendly development. ${ }^{74}$

\section{Low Absorptive Capacity}

In practice, even when host countries are able to successfully attract foreign technology investors, they may have difficulties in taking full advantage of new technologies. ${ }^{75}$ The localization of technologies is often costly and full of uncertainties. Although the risky experiment of adopting new technology generates positive spillovers in the form of an opportunity to "watch and learn," demanders are generally

\footnotetext{
69 The CDM serves as a critical forum for developing countries to import climate-friendly technologies. Foreign investors primarily aim at CERs in CDM projects. CERS have been purchased at subsistence levels in developing countries and then sold at global trading levels to earn huge profits for companies in the developed world.

70 IPCC Report, WGIII, ch. 1.5 (Barriers to the Transfer of Environmentally Sound Technologies, 2001).

71 Wenqiang Liu \& Ganb Lin, Cost-Competitive Incentives for Wind Energy Development in China: Institutional Dynamics and Policy Changes, 30 ENERGY POL'y 751 (2002).

72 W. Montgomery \& S. Tuladhar, Impact of Economic Liberalization on GHGs Emission Trends in India 2 (Climate Policy Centre ed., 2005).

73 Id.

74 Supra note 1, at 117.

75 Supra note 65, at 42.
} 
reluctant to engage in technology adaptation unless there is a positive return. ${ }^{76}$

In principle, low absorptive capacity stems from various factors, including law and extra-law ones. Taking China as an example! Factors like inefficiency in technology conversion and imperfect market mechanism mainly attribute to poor localization of advanced technologies. ${ }^{77}$ In addition, new technologies are operated in such a way that any given user's equipment interacts with that of other users so as to create network externalities. ${ }^{78}$ For example, the real attraction of vehicles which use alternative fuels depends on the available fueling facilities. Whether to establish these fueling facilities is, in turn, based on the future demands of vehicles. To accommodate newly-imported technologies, a package of physical infrastructure must be provided and should be, at the very least, integrated into national development plans. ${ }^{79}$ However, not all host countries can provide such network externalities at the ground level when asking for foreign climate technologies. For example, India's strategy to introduce biomass technologies nationwide was impossible in many rural areas where the supplies of electricity are intermittent or non-existent electricity. ${ }^{80}$ To integrate network externalities with technology plans is thus likely to increase occurrence and the successful rate of trans-boundary technology transaction.

\section{B. Poor Policy and Legal Framework}

Another commonly recognized challenge for host countries is to provide an adequately supportive regulatory context for climate technology transfer. To create and maintain such a context, these countries need to work on: (1) making overall feasible technology plans; (2) developing robust legislations; (3) readjusting foreign direct investment (FDI) and intellectual property policies in existence; and (4) providing sufficient incentives.

\section{Overall Feasible Plans for Climate Technologies}

"Many of [the] technology decisions we make today, whether in energy production, energy efficiency in buildings, transport, industry, or agriculture/forestry, will be in

76 Supra note 13, at 17.

77 Ming Yi, Xiaomeng Fang \& Yao Zhang, The Differentiated Influence of Technology Absorption on Regional Economic Growth in China, 11 Sustainabutry 12 (2019).

78 C. Tucker, Network Stability, Network Externalities and Technology Adoption 12 (NBER Working Paper No. 17246, 2011), available at https://www.nber.org/papers/w17246 (last visited on May 27, 2019).

79 Supra note 8, at 187.

80 Supra note 65, at 16. 
use for the rest of the current and even the next generation." ${ }^{\circledR 1}$ Successful technology transfer takes time and must be incorporated into national overall plans. The lessons learned from the implementation of the Montreal Protocol showed that "an impatient emphasis on quick results during planning may, at best, lead to disappointing results and, at worst, may lead to a failure to build strong relationships with and among key stakeholders that are a prerequisite to success. ${ }^{, 82}$

Although during last decades, policies, laws and regulations have been promulgated for both climate change and relevant technology in most host countries, the linkage between climate change and technology legislations seems weak and somehow superficial. ${ }^{83}$ Technology plans as important policy tools appear to be inconsistent, isolated from existing laws, and work as pure technology measures. For instance, China has adopted a comprehensive strategy for its national climate actions, by highlighting both climate change mitigation and adaption. However, specific technology plans overwhelmingly target mitigation technologies. In the area of agricultural management, for example, existing technology plans accommodate only climate mitigation technologies, which focus on reducing the GHGs emission from livestock and paddy farming. However, climate adaptation technologies aim to protect agricultural production. Local fiscal policies and intellectual property rights give rather slow and limited responses to climate technology plans. Moreover, the system integrity is inadequate both outside and within technology plans in existence. As far as mitigation technology plans are concerned, what have been set for renewable technologies reflect frequent shifts from domestic innovation to foreign transfer. $^{84}$ Thereafter, its trading policies such as tariff (wind turbine import duty) change too often to send clear and stable signals for international investors. The reason for poor and inefficient technology plans in those host countries can be partly attributed to locally weak decisions-making capacity. It can be understood that to make feasible plans for the development and transfer of climate technologies requires abundant researches and planning techniques. Working closely with the UNFCCC under the TNAs, for instance, is a pragmatic option for the plan-making organs in technology host countries. "This significant increase in the number of TNAs provides

81 R. Heintz, Key Challenges to Stimulating the Diffusion of Clean Technologies in Latin America, CALIDAD AmBIENTAL (ITESM) 2 (2000).

82 D. Strelneck \& P. Linquiti, Environmental Technology Transfer to Developing Countries: Practical Lessons Learned During Implementation of the Montreal Protocol 9 (1995).

83 Supra note 52, at 29-31.

84 Junfeng Li \& E. Martinot, Renewable Energy Policy Update for China, REnewable EnERgy News \& Information, July 21, 2010, available at http://www.renewableenergyworld.com/rea/news/article/2010/07/renewable-energy-policyupdate-for-China (last visited on Apr. 10, 2019). 
a platform for a more detailed and comprehensive review of technology needs identified at the regional level."

\section{Supportive and Robust Legislations}

A robust legal system is vital to deliver clear, stable and predictable signals for climate technology stakeholders, which ensures effective technology transfers in both short and long terms. First, legislations favoring climate technology transfer require climate change and relevant technology legislation as an integral part of development agenda. Although there have been gradually legal steps to achieve sustainable development goals in most host developing countries, climate change is rarely, in some occasions, one of these steps, because climate impacts are not parent in the short term. ${ }^{86}$ In countries where climate risks and damages are indistinct and often seen as distant, political actors still very much concentrate on immediate issues such as antipollutions that allow them to claim public resources and satisfy popular expectations. Even climate change and low carbon development have obtained attentions, of which technology solutions are not part. Virtually, in both theory and practice, sustainable development initiatives reduce the time to market for green products and technologies, which could increase the likelihood of successful technology transfer. ${ }^{87}$ Likewise, climate change initiatives contribute to relevant technologies and their dynamic transaction. In reality, climate change initiatives have found that technology development and transfer are neither clearly defined nor fully covered. ${ }^{88}$ Their potential contributions are undermined to a certain extent.

Second, the existing legislations must be assessed in a comprehensive manner and on this basis tailored to popularize climate mitigation and adaptation technologies. According to IPCC reports, the legal basis of host countries is unsound in general. Their climate/environmental legislations are lagging behind than the counterpartstechnology supplying countries. This gap is an undeniably formidable barrier for smooth international technology transfer. The legislations regulating climate technologies are various from environment/climate change laws, to economic arrangements and general technology laws. In China, for instance, there is no

85 UFCCC Secretariat, Expert Group on Technology Transfer Five Years of Work 3 (2007).

86 Supra note 1 , at 117.

87 N. Cantore et al., How Can Low-Income Countries Gain from a Framework Agreement on Climate Change? An Analysis with Integrated Assessment Modelling, 32 Dev. PoL'y Rev. 313 -26 (2014).

88 UNFCC, Recommendations of the Expert Group on Technology Transfer for enhancing the implementation of the framework for meaningful and effective actions to enhance the implementation of Article 4, paragraph 5, of the Convention, U.N. Doc. FCCC/SBSTA/2006/INF.4 (Aug. 26, 2006), available at https://unfccc.int/resource/docs/2006/ sbsta/eng/inf04.pdf (last visited on May 27, 2019). 
specialized climate change law on a national scale. The law-making process of the Climate Change Act has been undertaken since 2011 and its Draft was opened for public advice and professional suggestions for a long while. ${ }^{89}$ In the absence of a comprehensive Climate Change Act, domestic legislations are difficult to be coordinated with uniform [technology] objectives. At the international level, the Climate Change Act, which aims to address climate harms, contributes to increasing negotiation powers of governments and private enterprises advocating for foreign technologies. In other laws such as economic laws, their responses to climate technology development and transfer are also necessary. For instance, these laws are assumed to frame the CDM into national laws in a workable manner. ${ }^{90}$ In practice, the CDM growth is concentrated in China, India, Brazil \& South Korea (holding the largest percentage of global projects), while other developing countries (many in Sub-Saharan Africa) host fewer CDM projects. ${ }^{91}$ It is critical for countries with large CDM markets to recognize GHGs and CERs by property law and other laws like government procurement law. ${ }^{92}$ In a broader sense, such legal synergism from coal regulations, energy laws and technology laws is must, but absent generally or inadequate..$^{93}$

Finally, in the combat of climate change, the technology-based approach is a basically important tool just as the health-based approach, with which norms and standards are formulated. Ideally, factors like technological capacity, economic feasibility, and regulatory integrity and environment-health benchmarks would be comprehensively taken into account by norms and standard-makers. For instance, lax environmental standards are economically feasible, though they often fail to hold violators accountable. In general, environmental standards are lax and the cost for violation is unduly low. When it comes to GHGs emission standards, the International Organization for Standardization recently provided global benchmarks. ${ }^{94}$ China, as a response, issued national GHGs emission standards for coal-intensive sectors such as cement, steel, construction, and power generation. ${ }^{95}$ In available at $\mathrm{http}: / /$ news.china.com.cn/txt/2012-03/18/content_24923504_3.htm (last visited on Apr. 10, 2019).

90 Kyoto Protocol art. 12.

91 Supra note 35 , at 4.

92 Id.

93 Supra note 88, at 319-22.

94 T. Baumann \& A. Kollmuss, GHGs Schemes Addressing Climate Change: How ISO Standards Help, ISO Brochure 15-24 (2010).

95 China Governments, China Issues Its First 11th GHGs Emission Standards (Nov. 23, 2015), available at http://www. zgg.org.cn/bwdj_5137/gbwjgdwzzq/qgrdcwjg_9835/zfzx/201511/t20151123_554796.html (last visited on Apr. 10, 2019). 
these sectors, theoretically, there would be more opportunities for clean technology transfer. However, the reality shows a different picture, due to the lack of clear technology requirements and industry standards. In addition, $\mathrm{CO}_{2}$ is now deemed an atmospheric component instead of atmospheric pollutant. Existing air quality standards cannot be applied into controlling carbon emissions. ${ }^{96}$ Industry standards are updated not fast enough, particularly in comparison with the rapidly growing technology needs. The absence of standards hinders the acquisition, operation, and maintenance of newly imported technologies. ${ }^{97}$ The same situation occurs in the Philippine, whose clean technology standards have been scant and the enforcement of environmental regulations was poor due to the lack of standards available to validate claims of technology suppliers. ${ }^{98}$ To frame environmental standards in particular GHGs emission standards into technology requirements requires inclusive public participation in law-making process. In case of China, voices from scientists fail to be fully recognized. The interaction between environmental legislatures and scientists is historically missing and realistically blocked by the sector-split lawmaking practices. ${ }^{99}$ This situation has been gradually changed now with consistent amendments of environmental laws, legislation law and public participation procedural regulations.

\section{Readjustments on Foreign Investment and Trade Laws/Policies}

In practice, a significant portion of climate technology transfer is undertaken through traditional mechanisms such as FDI and technology trade. In particular, there are still potential uncertainties about non-commercial technology transfer under the UNFCCC system. ${ }^{100}$ Theoretically, globalization of technology requires "sensitive policies that seek to engage the major economic base of the nation or region with both indigenous and foreign technological capabilities."101 Policies and laws associated with climate technology transfer tend to be either heavily regulated or inadequately

96 Jiwen Chang, On the Control of Carbon Dioxide Discharge and Revision of the Air Pollution Control Act [二氧化碳 的排放控制与《大气污染防治法》的修订], 1 ThE ENVIRONMENTAL RULE OF LAW [中国环境法治] 72-86 (2009). $<$ available only in Chinese>

97 Bingqing Xin \& Yun Liu, Technology Needs of Developing Countries to Address Climate Change and Barriers of Technology Transfer [发展中国家气候变化技术需求及技术转移障碍], 26 ChINESE J. PopUlation, ResourCEs \& ENVTL [中国人口·资源与环境] 23 (2016).

98 N. Almanzor, Overcoming Barriers to the Diffusion of Clean Technologies in Developing Countries, 4th International Environment Technology Verification Forum and International Working Group on ETV Meeting 5 (2009).

99 Xiao Zhu \& Kaijie Wu, Public Participation in China's Environmental Lawmaking: In Pursuit of Better Environmental Democracy, 29 J. EnvtL L. 397-8 (2017).

100 Supra note 36, at 7. The price of climate related technologies arouses the issue of IPRs. Thus far, under the current UNFCCC, the dynamic transfer of climate related technologies, particularly the transfer on an international scale, does not take place fast enough under the business-as-usual to reach full potentials required by the UNFCCC.

101 Supra note 60, at 243. 
supervised. ${ }^{102}$ For instance, the legal arrangements on intellectual property protections in host countries are criticized for being weaker than the supplying countries. ${ }^{103}$ Sometimes, these intellectual property measures are seen as favoring local enterprises over foreign investors.

Less developed economies often seek to advantage themselves by protecting national champions while taking the fruits of others' inventiveness. The US was a latecomer to international intellectual property accords and was accused by Europeans of disrespect for their rights. ${ }^{104}$

In addition, host countries often establish registration systems to regulate and supervise foreign technology trade, through which local governments can examine technology import agreements and contracts to determine whether they correspond to the interests of their developing industry. ${ }^{105}$ Such registration systems are usually cumbersome, discouraging foreign technologies holders once in a while. For climate technologies, the relevant procedures must be simplified. Moreover, to increase the faith of foreign technologies holders, local property law is of particular concern. The uncertainties and risks of property law are suggested to be resolved for effective and long-term technology transactions. ${ }^{106}$

On a related point, it is important for host countries to make appropriate choices between FDI and technology licensing in accordance with national circumstances such as prevailing market structure and indigenous absorptive capacity. For instance, "a monopolistic market would be preferred in the case of FDI because here a defaulting licensee could cause a lot of harm." ${ }^{, 107}$ In contrast, technology licensing is a better option than FDI in the case of a competitive market and strong capacity to absorb technologies. In addition, the choice between FDI and technology import should follow technology life cycle. ${ }^{108}$ The different stages of a technology impact its

102 T. Forsyth, Enhancing Climate Change Technology Transfer through Greater Public-Private Cooperation: Lessons from Thailand and the Philippines, 29 NATURAL Resources F. 165-76 (2005).

103 UK Commission on Intellectual Property Rights, Integrating Intellectual Property Rights and Development Policy, Report of the Commission on Intellectual Property Rights 45-8 (2002).

104 R. Cass, Patent Reform with Chinese Characteristics-Beijing's Amended Intellectual Property Law Holds Dangers, Wall St. J., Feb. 10, 2009, available at https://www.wsj.com/articles/SB123419814824764201 (last visited on May 28, 2019).

105 Supra note 61 , at 222.

106 Id. at 220.

107 J. Wiener et al., Sharing Potential and the Potential for Sharing: Open Source Licensing as A Legal and Economic Modality for the Dissemination of Renewable Energy Technology, 18 Geo. InT'L EnvtL L. Rev. 277 (2006).

108 Supra note 13 , at 19. 
pricing and knowledge spill-overs. Technology licensees pay monopoly prices for intermediate technological products, while FDI end product prices are relatively low and could contribute more to the national welfare of host countries. ${ }^{109}$ In general, least developed countries ("LDCs") with limited innovative capacity and restrictive economic conditions need straightforward FDI more than they need technology licensing. This is why FDI is more realistic for them.

With regard to technology licensing, LDCs are more likely to benefit from technology and products in trade. Therefore, it is important to exempt LDCs from strong IPRs protection in order to reduce the monopoly prices of climate technologies. ${ }^{110}$ Middle-income developing countries, such as China, Brazil, and India, are now at the stage of technology imitation by duplication. Policymakers in those countries could incorporate FDI into domestic technology development, which would encourage a shift from pure duplication to creative imitation. ${ }^{111}$ With regard to technology licensing, on one side, existing alternatives in middle-income countries could bring licensing prices down for the sake of local competitive markets. On the other side, these technologies could develop higher value-added strategies at a lower cost. $^{112}$

\section{Economic Incentives}

Climate change project is characterized by "high development costs, high transaction costs and a large number of soft components." financing tools, which are principally aimed at less risky projects and expect a direct return. ${ }^{114}$ Very often, financial institutions in China are reluctant to provide initial capital for the use of transferred technologies, for uncertain inflation and interest rates, and risk aversion of banks. ${ }^{115}$ Although there are international finance tools available such as the Green Climate Fund, to harness these tools effectively seems knotty in reality. Carbon finance is a novel concept at which most host countries, particularly LDCs are inexperienced.

109 M. Grubb, Technology Innovation and Climate Change Policy: An Overview of Issues and Options, 1 KeIo J. Econ. 1720 (2004).

110 Supra note 13 , at $18-9$.

111 Id.

112 This always happens in labor-intensive export production, e.g., the southern east region of China where export-oriented productions are centralized.

113 Supra note 55, at 10558.

114 Supra note 82, at 5. This can be more problematic in the case of renewable energy projects and most especially in the case of land use projects.

115 M. Mancuso, The U.S.-China Clean Tech Opportunity, China Daily, Sept. 14, 2009, available at http://www. chinadaily.com.cn/opinion/2009-09/14/content_8689249.htm (last visited on Apr. 10, 2019). 
Governments who look for climate technologies are suggested to explore all possible incentives, to mobile public and private investments. ${ }^{116}$ In theory, there is a broad mixture of direct incentives such as subsidies, taxes, tariffs, and grants, as well as indirect incentives such as preferential procedures, information service and compliance assistance. ${ }^{117}$ In practice, the motivation of indigenous enterprises is not primarily strong-even the government is urging to scale clean technologies to mitigate and adapt climate damages. ${ }^{118}$ "In the presence of informational externalities, it may be optimal for a host country to subsidize the adoption of foreign technologies or else no one firm may be willing to bear the cost of technology adoption for fear of not making a positive return on its investment." 119 In this regard, both direct fiscal incentives and indirect assistance are bound to facilitate the process of technology transfer at enterprises level. Unfortunately, climate technology transfer is often poorly incentivized in host countries, ${ }^{120}$ partly due to the fact that carbon markets are generally undeveloped for demand-driven, profit-based incentives to create a winwin situation and attract the voluntary participation of industries.

\section{Weak Implementation and Enforcement}

The implementation and enforcement are the life of environment laws wherever they have been promulgated. This is probably even truer in host countries [of climate technology]. Many factors affect the effectiveness of implementation and enforcement. From a legal perspective, these factors include legislative quality (i.e., number, specificity and influence), institutional capacity (i.e., administrative structure, sectoral coordination, efficiency) and judiciary system (i.e., non-miscarriage of justice, judicial activism) ${ }^{121}$ Potential barriers become more formidable at the subnational level, due to weaker capacities and racing interests. For example, in Africa, there is an urgent need to improve national regulatory environment in relation to regional

116 N. Islam et al., Environmental Law in Developing Countries, Selected Issues, Environmental Policy and Law 144-7 (IUCN ed., 2001).

117 IPCC Report, WGIII, ch. 1.5 (Barriers to the Transfer of Environmentally Sound Technologies, 2001).

118 Linna Xie \& Saixing Zeng, Technology Transfer in Clean Development Mechanism Projects: Lessons from China, 19 TeCh. \& ECON. Dev. ECONOMY 479-82 (2013).

119 Supra note 13 , at 16-7.

120 U.N. Doc. FCCC/SBI/2010/INF.4 (May 26, 2010). In host developing countries, the political capital and the mandate of environmental regulators, particularly at the central state level, is weak compared to finance or line ministries and their industrial partners.

121 UNFCC, Recommendations of the Expert Group on Technology Transfer for enhancing the implementation of the framework for meaningful and effective actions to enhance the implementation of Article 4, paragraph 5, of the Convention, U.N. Doc. FCCC/SBSTA/2006/INF.4 (Aug. 26, 2006), available at https:/unfecc.int/resource/docs/2006/ sbsta/eng/inf04.pdf (last visited on May 27, 2019). 
approaches. $^{122}$

As some of the implementation and enforcement barriers are not purely legal, their solutions thus are beyond the scope of law (i.e., political stability, social feasibility). As early as 1992, the US funded an initiative to evaluate how farmers in Burkina Faso could use climate forecasts to improve food security and agricultural sustainability. ${ }^{123}$ When this initiative was carried out, a series of barriers emerged as a result of village politics and ethnic identity. ${ }^{124}$ To improve implementation and enforcement, lawmakers are intended to seriously consider social feasibility and cultural acceptability needed for accommodating foreign climate technologies. Cultural acceptability is determined by local tradition, dominant values and public awareness. Specifically, examples that impact the cultural acceptability of climate technology are like economy-centered development ideal, poor accountability of enterprises on energy conservation and resources reduction (in particular of smallmiddle size enterprises), repulsion of society against new varieties/technologies and poor protection on knowledge and public good. ${ }^{125}$ For example, in the Philippines, low carbon technologies are commonly perceived as greater risks by the public because they have not yet been proven by practice. ${ }^{126}$ The repulsive and conservative perception of technology hamper carbon-intensive technologies from being phased out, because the recipients are reluctant to keep up with current performance standards. ${ }^{127}$ In China, poor protection on knowledge and intellectual property is deeply embedded in the traditional culture. "Those that steal book for reading are not regarded as thieves," as advocated by the well-known Confucius. According to Confucius, books as collections of knowledge should be spread publically. In recent, the priority attached to economic growth contributes to carbon 'lock-in' effects in large. ${ }^{128}$ This situation has been changing under the profound 'Ecological Reformations' which aim to integrate environment accounts into government performances assessment and then restructure administrative system. The prevalent

122 Ad Hoc Working Group on Long-Term Cooperative Action under the Convention, Contact Group on Enhanced Action on Technology Development and Transfer (Nov. 6, 2009), available at http://unfccc.int/files/meetings/ad_hoc working_groups/lca/application/pdf/awglcattnp47061109.pdf (last visited on May 27, 2019).

123 UNFCC, Enabling Environments for Technology Transfer, U.N. Doc. FCCC/TP/2003/2 (Feb. 4, 2003), available at https://unfccc.int/resource/docs/tp/tp0302.pdf (last visited on May 27, 2019).

124 Id. at 105.

125 Id.

126 Supra note 99 , at 5.

127 Academically, it is extremely difficult to obtain conclusive evidences, and reach an overall vision of this consequential barrier. A tailored response is required for a greater likelihood of effective technology transfer in these host countries.

128 L. Westman, Can China Break Its Carbon Lock-Ins? in Advancing Sustainable Business in China 61(China Dialogue ed., 2013). 
idea that GDP is king is eliminating through top-down actions, which calls for broader bottom-up efforts. Intensive bottom-up actions are the key to solving 'uninformed transfer,' thereby ensuring social feasibility and acceptability. A study conducted on technology transfer projects between Korea and the Philippines suggests the necessity of participatory governance mechanism between public, private and voluntary sectors. ${ }^{129}$ International climate technology transfer should be "approached by intensive bottom-up methodologies from the local communities and the recipient country governments rather than by top-down methodologies from the donor country."

\section{Conclusion}

The UNFCCC, and its recent achievement the Paris Agreement, aims to achieve a healthy, sustainable climate situation on a global scale. In this process, the international transfer of climate friendly technologies plays a crucial role. Because of immature world carbon market and young climate legal framework, however, climate technology transfer is confronting various barriers in practices. The situation is getting worse in host [demander] countries, which are mostly developing countries in reality. These countries have inadequate capacity, but urgently appeal for up-todate technologies to overcome the domestic 'lock-in' effects of high carbon.

Due to enormous differences and inadequate information available, it is impossible to provide one-size-fits-all analysis for all legal barriers faced by host developing countries in the acquisition of climate technologies. However, "what remains common to all cases is the desirability of a supportive regulatory framework, and enabling environment more generally, together with the circulation of knowledge and capabilities among individuals and institutions in host countries." "131 This article has thus focused on identifying those commonly-recognized and critical barriers; assessing and analyzing their counterproductive impacts on technology transfer; and in some cases, trying to provide viable solutions.

In summary, there are significant barriers that potentially hinder a meaningful

129 T. Huh \& H. Kimwo, Korean Experimentation of Knowledge and Technology Transfer to Address Climate Change in Developing Countries, 10 Sustainablity 5-12 (2018).

130 Id. at 11 .

131 GEF, Elaboration of a Strategic Program to Scale up the Level of Investment in the Transfer of Environmentally Sound Technologies, GEF/C.34/05/Rev.01 (Nov. 13, 2008), available at https://www.thegef.org/sites/default/files/councilmeeting-documents/C.34.5.Rev_.1_4.pdf(last visited on May 27, 2019). 
and effective acquisition of climate technologies, ranging from inadequate capacity, poor regulatory framework, insufficient incentives, to weak implementation and enforcement. All these barriers are not purely legal in a real word scenario. Some barriers are extra-law in essence, such as information asymmetry and capacity deficiency. These barriers could be resolved with broader government policies and/ or infrastructures development. To enable environment is thus a systemic process (Figure 1). To a greater or less extent, the barriers result from the characters of climate technologies. For instance, the scope of climate technologies is boundless and the prices of these technologies are incomplete. ${ }^{132}$ Whereby, "the implicit or perceived disagreement on what constitutes technology transfer-and hence what are the technology-related obligations under the UNFCCC-might be at the heart of some of the contentiousness around technology institutions in the UNFCCC." 133

The increase of climatic crisis and the shifting terrain of global governance are creating both ecological and legal uncertainty. As major advocators of climate technology transfer, host countries have interests in exploring, assessing, and overcoming potential legal barriers, which prepares them better for national determined contributions in the post-Paris era. In a legislative term, the UNFCCC proceedings may review their approach to solve problems. As one observer said: "To be properly inclusive and relatively effective, it dominant regulatory approach at the global level to tackling climate change needs to be designed to take account of the regulatory weakness of developing countries and not the regulatory strengths of the developed world." ${ }^{\prime 134}$ The Paris Agreement and its implementation are making efforts towards this direction, through the progressive arrangement of enabling environment. Now is time to practically encourage local technology recipients and host country governments to have ownership of the solutions.

132 The carbon market is mainly driven by statutory intervention such as the UNFCCC framework. However, the international climate framework has so far been less robust, which causes a high degree of uncertainty for these technologies. As far as host countries are concerned, acquiring and adopting technology is a process of integration, requiring good faith and diligent cooperation from either governments or the private sector. Therefore, the barriers faced by recipients take place not as isolated phenomena but in a comprehensive way.

133 Supra note 36 , at 8.

134 Supra note 7, at 111. 
Figure 1: Process of Enabling Environment ${ }^{135}$

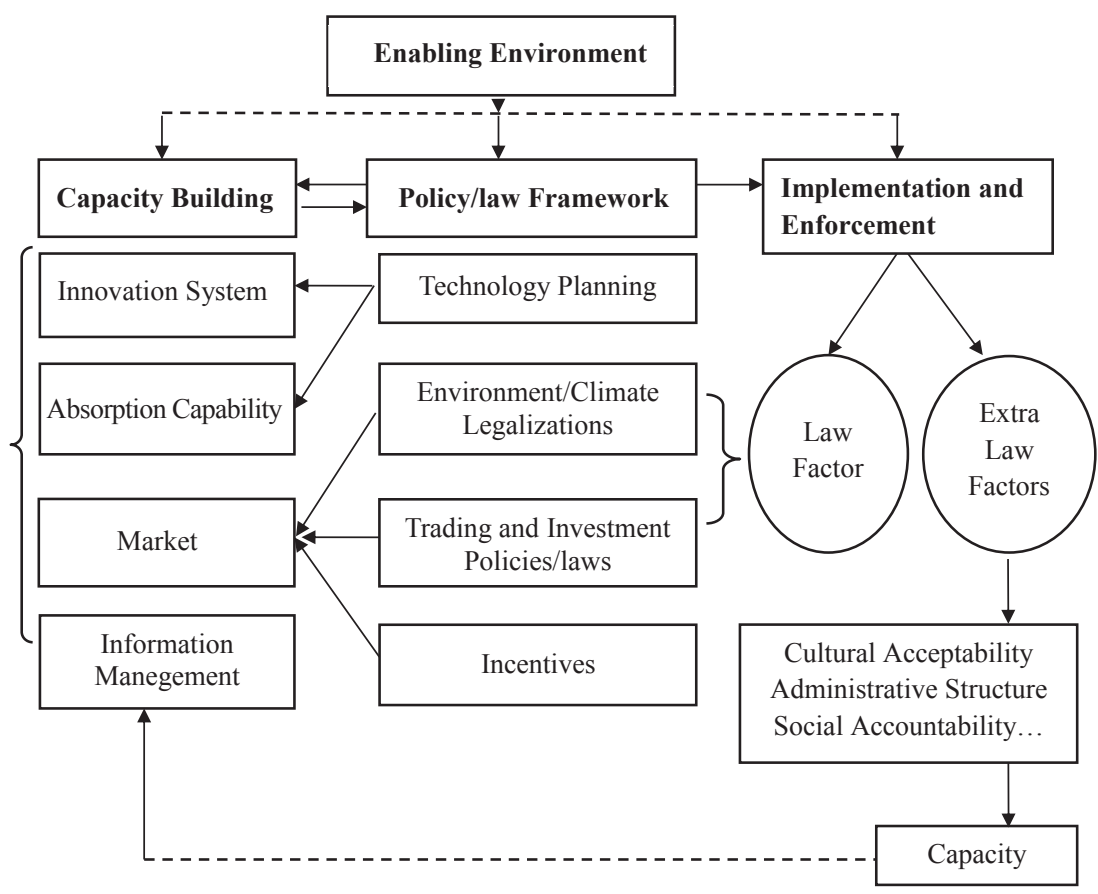

135 Compiled by the author. 